\title{
Evaluation of Uterine Cavity in Infertile Women: Comparison of Transvaginal Ultrasound, Saline Contrast Hystero-Sonography and Hysteroscopy-A Tunisian Series
}

\author{
Raja Briki, Ons Cherif*, Salma Chachia, Mohamed Bibi, Sassi Boughizane, Abedeljalil Khlifi, \\ Hedi Khairi
}

Gynecology and Obstetrics Department of Farhat Hached University Hospital Center, Sousse, Tunisia

Email: *onscherifb@gmail.com

How to cite this paper: Briki, R., Cherif, O., Chachia, S., Bibi, M., Boughizane, S., Khlifi, A. and Khairi, H. (2018) Evaluation of Uterine Cavity in Infertile Women: Comparison of Transvaginal Ultrasound, Saline Contrast Hystero-Sonography and Hysteroscopy-A Tunisian Series. Open Access Library Journal, 5: e4826.

https://doi.org/10.4236/oalib.1104826

Received: August 4, 2018

Accepted: August 26, 2018

Published: August 29, 2018

Copyright $\odot 2018$ by authors and Open Access Library Inc.

This work is licensed under the Creative Commons Attribution International License (CC BY 4.0).

http://creativecommons.org/licenses/by/4.0/

\begin{abstract}
The development of uterine pathologies usually involves transvaginal ultrasonography, possibly supplemented by hysteroscopy. Recent technical developments in ultrasound have given rise to a new exploration technique: hysterosonography or ultrasound with contrast enhancement. Hysterosonography has emerged today in the study of the uterine cavity with a precise analysis of the endometrial mucosa and related pathologies. Objectives: To determine the contribution of hysterosonography in uterine cavity pathologies, and appraise the performance of this examination in the evaluation of the uterine cavity by comparing it to vaginal ultrasound and diagnostic hysteroscopy. A retrospective study of 39 hysterosonography examinations was performed in the Gynecology and Obstetrics Department of Farhat Hached University Hospital Center, Sousse, Tunisia. Included in the study were patients suffering from infertility. During the period of the clinical trial, 39 patients were potential candidates for this study. The mean age of the patients was 31.5 years. In case of hypofertility associated with endometrial polyps, the hysterosonography/histology concordance was of $51.4 \%(13 / 24)$. The statistical values of the hysterosonography were: sensitivity: $76.9 \%$, specificity: $27.2 \%$, VPP: $55.5 \%$, and VPN: 50\%. In case of uterine malformation, hysterosonography allowed the diagnosis to be made in three cases, with a sensitivity of $100 \%$, but the number of these abnormalities was limited and the statistical value was low. In clinical practice, combining hysterosonography with transvaginal ultrasound may increase the sensitivity of the latter, thus avoiding
\end{abstract}


unnecessary diagnostic hysteroscopies. It is likely to significantly reduce the indications for diagnostic hysteroscopy, a test that is not devoid of morbidity.

\section{Subject Areas}

Gynecology \& Obstetrics

\section{Keywords}

Hysterosonography, Uterine Cavity Pathologies, Infertility

\section{Introduction}

The study of the endometrium and the uterine cavity has largely benefited from the contribution of transvaginal ultrasound, which is currently the first-line examination in the exploration of abnormal uterine bleeding, pelvic pain and infertility. If this vaginal ultrasound allows a satisfactory study of the uterine cavity and the surrounding myometrium which in the majority of cases are due to the natural contrast of the endometrium, the interpretation of the uterine lining may be difficult, and other investigations may have to be conducted. Thus, the hysteroscopy will be carried out in second intention. In fact, hysteroscopy allows a direct visualization of the uterine cavity and the realization of specimens of the endometrium for histological study. Known since 1981 [1], hysterosonography has now gained some notoriety. The idea was suggested by the observation of small fluid laminae in menopausal women. The presence of this physiological fluid, in case of old menopause, allows a perfect study of the cavity [2] [3]. The injection into the uterine cavity of a contrast agent under echography control makes it possible to distend and provide an artificial contrast allowing better visualization of the endometrium and endocavitary abnormalities. The important number of these explorations has led to a multiplication of its prescriptions, which are often redundant [4] [5]. In our context, hysterosonography seems to be a practical and interesting examination of the endometrial lesions due to its technical and financial accessibility. In order to study its contribution to the pathologies of the uterine cavity in case of infertility, we carried out this prospective study. The main objective of the present study is to evaluate the diagnostic performance of hysterosonography in the evaluation of the uterine cavity as compared to vaginal echography and hysteroscopy, which are considered to be the reference examination when it comes to exploring the uterine cavity.

\section{Methods}

1) Study design

This is a retrospective clinical study conducted in our Gynecology-Obstetric department at Farhat Hached University Hospital Center. Sousse, Tunisia, from January 1st, 2016 to November 30th, 2016. 


\section{2) Population}

Eligible patients were recruited among the women who were medically followed up in our department and presented a clinical suspicion of a pathology of the mucosa and/or the submucosal uterus in the context of exploring primary or secondary hypo fertility. The patients with incomplete medical record, those who refused to participate, or those we lost track of during the duration of the study were not included. We also excluded from the study patients with cervical and vaginal infection, or impassable cervical stenosis.

3) Protocol of the study

We performed, on all patients, a suprapubic and endo-vaginal ultrasound in first intention. Than we completed with a hysterosalpingography. All patients underwent hysterosonography with an injection of a contrast agent (9\%o physiological saline solution) using an injection catheter: the intrauterine insemination catheter PM IU PS 1260600 (PM IU-Intrauterine Insemination Catheter Without PS 1260600 2/CH6 $1.6 \mathrm{~mm} / 0.40 \mathrm{ml} 45 \mathrm{~mm}$ PRINCE MEDICAL SAS ZA). The hysterosonography was performed without any premedication or anesthesia. All patients benefited from a diagnostic and/or operative hysteroscopy with or without histological specimen.

4) Evaluation methods

We evaluated the diagnostic value of hysterosonography by calculating sensitivity (SEN), specificity (SP), positive predictive value (VPP), and negative predictive value (VPN). Sensitivity favored in our study as hysterosonography is considered to be an orientation test. A sensitivity greater than/or equal to $80 \%$ is considered excellent [6]. We also studied the concordance between the results of the hysterosonography, the results of the hysteroscopy, and the histology finding.

5) Statistical analysis

The statistical analysis was carried out using the software Statistica 6.1 (Stat Soft, France). For the quantitative variables, the results were expressed in averages and their standard deviations. Qualitative variables were expressed in percentages and frequencies. The processing of the data was carried out as follows:

- The t-test was used to analyze the effect of the variables.

-All statistical tests wereconsidered significant with a probability value of less than $0.05(\mathrm{p}<0.05)$.

Statistical methods for the evaluation of radiological complementary examinations were sensitivity, specificity and positive and negative predictive values.

All patients gave her informed written consent. This study was approved by the Human research Ethics Committee, the University of Medicine of Sousse, Tunisia.

\section{Results}

During the period of the clinical trial, 39 patients were potential candidates for this study. The mean age of the patients was 31.5 years. 
Regarding hysterosonography, no complication whether infectious or hemorrhagic were observed during the examination. For hysteroscopy, a case of hemorrhage was noted in relation to a cervical tear that was repaired and had a favorable evolution. In this group, hysterosonography was normal in 13 cases and pathological in 28 patients. The results of Hysterography are resumed in Table 1.

1) Case of the endometrial polyp

In case of subfertility associated with endometrial polyps, the hysterosonography/histology concordance is of $51.4 \%$ (13/24). The statistical values of the hysterosonography were: sensitivity: $76.9 \%$, specificity: $27.2 \%$, VPP: $55.5 \%$, and VPN: $50 \%$. The Confrontation Hysterosonography and Histology in case of hypofertility associated with a polyp of the endometrium is summarized in Table 2.

2) Case of intracavitarymyoma

The match between hysterosonography and histology is, in this context and particularly this association, $60 \%(9 / 15)$. The statistical values of the hysterosonography were: sensitivity: 54.5\%, specificity: 75\%, VPP: $85.7 \%$, and VPN: $37.5 \%$. Table 3 resumes the confrontation Hysterosonography and Histology in

Table 1. Results of hysterosonography in case of infertility.

\begin{tabular}{cc}
\hline Hysterosonography & Number of case \\
\hline Normal endometrium & 33 \\
Hypertrophy of the endometrium & 3 \\
Polyp of the endometrium & 18 \\
Intracavitary myoma & 7 \\
Uterine malformation & 3 \\
Uterine synechia & 0 \\
\hline
\end{tabular}

Table 2. Confrontation Hysterosonography/Histology in case of hypofertility associated with a polyp of the endometrium.

\begin{tabular}{ccccc}
\hline \multirow{3}{*}{ Hysterosono } & \multicolumn{3}{c}{ Histology } \\
\hline \multirow{3}{*}{} & YES & 10 & NO & Total \\
& NO & 3 & 8 & 18 \\
& Total & 13 & 3 & 6 \\
\hline
\end{tabular}

Table 3. Confrontation Hysterosonography/Histology in case of hypofertility associated with intracavitarymyoma.

\begin{tabular}{lcccc}
\hline \multirow{3}{*}{ Hysterosono } & \multicolumn{3}{c}{ Histology } \\
\hline & YES & 10 & NO & Total \\
& NO & 3 & 8 & 18 \\
& Total & 13 & 3 & 6 \\
\hline
\end{tabular}


case of hypofertility associated with intracavitarymyoma.

3) In case of uterine malformation

Hysterosonography allowed the diagnosis to be made in three cases, with a sensitivity of $100 \%$, but the number of these abnormalities is limited and the statistical value is low.

\section{Discussion}

Infertility is an important indication for hysterosonography in our department, with 39 candidates, and a frequency of 59\%. The use of hysterosonography in these patients led to the etiological diagnosis with an excellent sensitivity and specificity of $81.8 \%$ and $91.7 \%$, respectively. The correlation with hysteroscopy is good, $87.9 \%$ of cases, which is consistent with rates reported by most authors. El Sherbiny [7], who conducted a study on 180 women and investigated intrauterine lesions using hysterosonography in women with hypofertility, reported a sensitivity of $75 \%$ and a specificity of $100 \%$. Bignol [8] found a sensitivity and specificity of $98 \%$ and $83 \%$, respectively, in a study carried out on 346 patients. However, in a study performed on 77 hypo fertile women, Ahmadi et al. [9] was able to diagnose 124 uterine abnormalities in a set of 133 revealed during hysteroscopy; the sensitivity was $68.4 \%$ and the specificity was $96.3 \%$. In two similar studies, Guven et al. [10] found sensitivity of $90 \%$ and specificity of $40 \%$, while Acholonu et al. [11] found a sensitivity of $81.8 \%$ and a specificity of $93.8 \%$. Hysterosonography has also shown interesting results in verifying the integrity of the uterine cavity in hypo fertile women candidates for assisted reproductive technology (PMA). Indeed, in a series of candidates for In Vitro Fertilization (IVF), Ayida et al. [12] found $42 \%$ of intra-uterine lesions detected via hysteroscopy. The impact of endocavitary abnormalities and the benefit of their management on embryonic implantation rates are the subject of numerous studies. Their results, although sometimes divergent, justify carrying out an exploration of the uterine cavity within the framework of an AMP technique or in case of repeated failures of implantation in IVF. In spite of a first uterine assessment carried out before any management in AMP, we found about 50\% of morphological or histological uterine lesion during the failure of implantation [13] [14]. Several studies have demonstrated a decrease in the rate of implantation in the presence of intrauterine abnormalities in patients with repeated implantation failures [15] and an improvement in the rate of pregnancy around 55\% after treatment [15] [16] [17]. The exploration of the uterine cavity is essential to detect any abnormalities. Hysterosonography allows a significant improvement in diagnostic accuracy compared to conventional 2D vaginal ultrasound. Thus, in a study by Ayida et al. [12], the authors compare the contribution of hysterosonography and hysteroscopy in the detection of intrauterine lesions before IVF. They found a sensitivity of hysterosonography of $87.5 \%$, a specificity of $100 \%$, a VPP of $100 \%$ and a VPN of $91.6 \%$. The two lesions unrecognized by hysterosonography in this study were minor lesions: minor synechia and submucosal fi- 
broma, lesions for which it has not yet been proven that the treatment improved the implementation rates. Other authors [18] compared hysterosonography and hysterography in the detection of intrauterine lesions in a group of 320 females who were candidates for in vitro fertilization with spermatic injection (ICSI) for male indication. Hysteroscopy was performed in case of a pathology detected by hysteroscopy or hysterosonography. The rate of pregnancy was identical in the hysterography and hysterosonography groups, and the authors concluded that hysterosonography is a simple, inexpensive and less risky alternative than hysterography for the evaluation of the uterine cavity before IVF.

1) Endocavitary abnormalities: endometrial polyps, submucosalmyomas, synechiae:

There is a probable, but not demonstrated, effect of these endocavitary abnormalities on fertility. Hysteroscopic intervention is widely practiced [19] [20]. Seshadri also studied the diagnostic value of hysterosonography in the detection of all endo-uterine abnormalities [21]. The results came up with very good diagnostic qualities, with a sensitivity of $88 \%$ (95\% CI [0.85 - 0.90]) and a specificity of $94 \%(95 \%$ CI $[0.93-0.96])$.

2) Tubular permeability

Tubal permeability disorders play a role in 12 - 33\% of infertile couples [22]. Its evaluation is the basis for therapeutic decision: in the absence of permeable proboscis, the couples are oriented directly towards the IVF, while less severe alternatives are possible in the opposite case. Evaluation is systematic prior to any intervention which could create the need for a simple, rapid and well tolerated technique [23]. The diagnostic interest of hysterosonosalpingography, was studied in the Maheux-Lacroix meta-analysis published in 2014 [24]. It lists 28 studies including a total of 1551 women and 2740 tubes. The combined sensitivity and specificity estimates of tubal contrast ultrasound ("Sono-HSG") compared to laparoscopy-Blue Test (EB) were $92 \%$ (95\% CI [0.82 to 0.96]) and 95\% (95\% CI [0.90 - 0.97]), respectively. In nine studies (582 women, 1055 tubes), tubal contrast ultrasonography and hysterosalpingography were both compared with laparoscopy-EB, giving no significant difference between these two techniques in terms of sensitivity and specificity (P 0.4). Thus, hysterosonography may also be proposed to evaluate tubal permeability. The use of a balloon catheter and a positive contrast agent facilitates this study [25]. Indeed, the diagnostic profitability of the hysterosonography is considered average with a physiological saline, of the order of $79 \%$ [25]. Note that several authors assume that $3 \mathrm{D}$ hysterosonography improves the diagnostic performance of hysterosonography [25]. In a prospective study carried out on 268 patients, 3D hysterosonography improved the performance of hysterosonography in the diagnosis of endo-uterine pathologies. In fact the sensitivity rose from $93.6 \%$ to $97.9 \%$ and the specificity from $97.3 \%$ to $100 \%$. This technique increased the visualization sensitivity of uterine synechiae and decreased examination time and patient discomfort [26]. Moreover, according to Panchal [27], the $3 \mathrm{D}$ mode has several advantages; the re- 
ported possible benefits are: increased inter and intra-observer reproducibility, shorter learning curve with better accessibility to less experienced operators, better visibility of the passage of the contrast product in the tubes and visualization of the full extent of the tube on the 3D images, reduction of the procedural time (but increase of the post-treatment), economy of contrast product, improvement of patient comfort (less leakage of product) and possibility to replay the images offline.

\section{Conclusions}

These conclusions highlight the essential role of hysterosonography in the exploration of endo-uterine anomalies, since it reliably assesses the size, the location and the number of intracavitary lesions and their types, and provides an indication of the most appropriate treatment.

In clinical practice, coupling hysterosonography to endovaginal ultrasonography may increase sensitivity, avoiding unnecessary diagnostic hysteroscopies, a test that is not devoid of morbidity. On the other hand, its contribution in the exploration of tubal permeability remains controversial because it has proved not only to have limitations but also not to be very reproducible.

\section{Competing Interests}

The authors declare no competing interest.

\section{References}

[1] Nannini, R., Chelo, E., Branconi, F., Tantini, C. and Scarselli, G.F. (1981) Dynamic Echohysteroscopy: A New Diagnostic Technique in the Study of Female Infertility. Acta Europaea fertilitatis, 12, 165-171.

[2] Goldstein, S.R. (1994) Use of Ultrasonohysterography for Triage of Perimenopausal Patients with Unexplained Uterine Bleeding. American Journal of Obstetrics \& Gynecology, 170, 565-570. https://doi.org/10.1016/S0002-9378(94)70228-4

[3] Laing, F.C., et al. (1980) Ultrasonic Demonstration of Endometrial Fluid Collections Unassociated with Pregnancy. Radiology, 137, 471-474. https://doi.org/10.1148/radiology.137.2.7433679

[4] Laifer-Narin, S.L., Ragavendra, N., Lu, D.S., Sayre, J., Perrella, R.R. and Grant, E.G. (1999) Transvaginal Saline Hysterosonography: Characteristics Distinguishing Malignant and Various Benign Conditions. AJR American Journal of Roentgenology, 172, 1513-1520. https://doi.org/10.2214/ajr.172.6.10350282

[5] Bernard, J.P., Lecuru, F., Darles, C., Robin, F., De Bievre, P. and Taurelle, R. (1997) Saline Contrast Sonohysterography as First-Line Investigation for Women with Uterine Bleeding. Ultrasound in Obstetrics \& Gynecology, 10, 121-125. https://doi.org/10.1046/j.1469-0705.1997.10020121.x

[6] Turcotte, G. and Bouchard, M. (1979) Le diagnostic médical. Modèle d'évaluation des procédures diagnostiques cliniques et techniques. Union Med Can., 108, 515-519.

[7] El-Sherbiny, W. and Nasr, A.S. (2011) Value of 3-Dimensional Sonohysterography in Infertility Work-Up. Journal of Minimally Invasive Gynecology, 18, 54-58. 
https://doi.org/10.1016/j.jmig.2010.08.697

[8] Bingol, B., Gunenc, Z., Gedikbasi, A., Guner, H., Tasdemir, S. and Tiras, B. (2011) Comparison of Diagnostic Accuracy of Saline Infusion Sonohysterography, Transvaginalsonography and Hysteroscopy. Journal of Obstetrics and Gynaecology, 31, 54-58. https://doi.org/10.3109/01443615.2010.532246

[9] Ahmadi, F., Rashidy, Z., Haghighi, H., Akhoond, M., Niknejadi, M., Hemat, M., et al. (2013) Uterine Cavity Assessment in Infertile Women: Sensitivity and Specificity of Three-Dimensional Hysterosonography versus Hysteroscopy. Iranian Journal of Reproductive Medicine, 11, 977.

[10] Guven, M.A., Bese, T., Demirkiran, F., Idil, M. and Mgoyi, L. (2004) Hydrosonography in Screening for Intracavitary Pathology in Infertile Women. International Journal of Gynecology \& Obstetrics, 86, 377-383.

https://doi.org/10.1016/j.ijgo.2004.05.005

[11] Acholonu, U.C., Silberzweig, J., Stein, D.E. and Keltz, M. (2011) Hysterosalpingography versus Sonohysterography for Intrauterine Abnormalities. Journal of the Society of Laparoendoscopic Surgeons, 15, 471. https://doi.org/10.4293/108680811X13176785203923

[12] Ayida, G., Chamberlain, P., Barlow, D. and Kennedy, S. (1997) Uterine Cavity Assessment Prior to In Vitro Fertilization: Comparison of Transvaginal Scanning, Saline Contrast Hysterosonography and Hysteroscopy. Ultrasound in Obstetrics \& Gynecology, 10, 59-62. https://doi.org/10.1046/j.1469-0705.1997.10010059.x

[13] Makrakis, E. and Pantos, K. (2010) The Outcomes of Hysteroscopy in Women with Implantation Failures after In-Vitro Fertilization: Findings and Effect on Subsequent Pregnancy Rates. Current Opinion in Obstetrics and Gynecology, 22, 339-343. https://doi.org/10.1097/GCO.0b013e32833beaa3

[14] Demirol, A. and Gurgan, T. (2004) Effect of Treatment of Intrauterine Pathologies with Office Hysteroscopy in Patients with Recurrent IVF Failure. Reproductive BioMedicine Online, 8, 590-594. https://doi.org/10.1016/S1472-6483(10)61108-X

[15] Cenksoy, P., Ficiciglu, C., Yildirim, G., Yesiladali, M., et al. (2013) Hysteroscopic Findings in Women with Recurrent IVF Failures and the Effect of Correction of Hysteroscopic Findings on Subsequent Pregnancy Rates. Archives of Gynecology and Obstetrics, 287, 357-360. https://doi.org/10.1007/s00404-012-2627-5

[16] Soares, S.R., MessalaBatsita Barbosa dos Reis, M. and Camargos, A. (2000) Diagnostic Accuracy of Sonohysterography, Transvaginal Sonography, and Hysterosalpingography in Patients with Uterine Cavity Diseases. Fertility and Sterility, 73, 406-411. https://doi.org/10.1016/S0015-0282(99)00532-4

[17] Hosseini, M.A., Eddirimi, N., Mahdavi, A., Aleyasin, A., Safdarian, L., Fallahi, P., et al. (2014) Hysteroscopy in Patients with Repeated Implantation Failure Improves the Outcome of Assisted Reproductive Technology in Fresh and Frozen Cycles. Journal of Obstetrics and Gynaecology Research, 40, 1324-1330.

[18] Alatas, C., Urman, B., Aksoy, S., Mercan, R. and Nuhöglu, A. (1998) Evaluation of Uterine Cavity by Sonohysterography in Women Scheduled for Intracytoplasmic Sperm Injection. Human Reproduction, 13, 2461-2462.

https://doi.org/10.1093/humrep/13.9.2461

[19] Jayaprakasan, K., Polanski, L., Sahu, B., Thornton, J.G. and Raine-Fenning, N. (2014) Surgical Intervention versus Expectant Management for Endometrial Polyps in Subfertile Women. Cochrane Database of Systematic Reviews, 8, CD009592.

[20] Bosteels, J., Kasius, J., Weyers, S., Broekmans, F.J., Mol, B.W.J. and D'Hooghe, T.M. (2013) Hysteroscopy for Treating Subfertility Associated with Suspected Major Ute- 
rine Cavity Abnormalities. Cochrane Database of Systematic Reviews, 1, CD009461.

[21] Seshadri, S., El-Toukhy, T., Douiri, A., Jayaprakasan, K. and Khalaf, Y. (2015) Diagnostic Accuracy of Saline Infusion Sonography in the Evaluation of Uterine Cavity Abnormalities Prior to Assisted Reproductive Techniques: A Systematic Review and Meta-Analyses. Human Reproduction Update, 21, 262-274.

https://doi.org/10.1093/humupd/dmu057

[22] Emanuel, M.H. and Exalto, N. (2011) Hysterosalpingo-Foam Sonography (HyFoSy): A New Technique to Visualize Tubal Patency. Ultrasound in Obstetrics \& Gynecology, 37, 498-499. https://doi.org/10.1002/uog.8912

[23] Monte, G.L., Capobianco, G., Piva, I., Caserta, D., Dessole, S. and Marci, R. (2015) Hysterosalpingo Contrast Sonography (HyCoSy): Let's Make the Point! Archives of Gynecology and Obstetrics, 291, 19-30. https://doi.org/10.1007/s00404-014-3465-4

[24] Maheux-Lacroix, S., Boutin, A., Moore, L., Bergeron, M.-E., Bujold, E., Laberge, P., et al. (2014) Hysterosalpingosonography for Diagnosing Tubal Occlusion in Subfertile Women: A Systematic Review with Meta-Analysis. Human Reproduction, 29, 953-963. https://doi.org/10.1093/humrep/deu024

[25] Benkaddour, Y.A., Gervaise, A. and Fernandez, H. (2010) Exploration de la cavité utérine dans le bilan d'infertilité: Quel examen choisir? Journal de Gynécologie Obstétrique et Biologie de la Reproduction, 39, 606-613.

https://doi.org/10.1016/j.jgyn.2010.08.004

[26] Ahmadi, F. and Javam, M. (2014) Role of 3D Sonohysterography in the Investigation of Uterine Synechiae/Asherman's Syndrome: Pictorial Assay. Journal of Medical Imaging and Radiation Oncology, 58, 199-202. https://doi.org/10.1111/1754-9485.12137

[27] Panchal, S. and Nagori, C. (2014) Imaging Techniques for Assessment of Tubal Status. Journal of Human Reproductive Sciences, 7, 2-12.

https://doi.org/10.4103/0974-1208.130797 